\title{
Transcription Factor Short Stature Homeobox 2 Is Required for Proper Development of Tropomyosin-Related Kinase B-Expressing Mechanosensory Neurons
}

\author{
Alexandra Scott, ${ }^{1 \star}$ Hiroshi Hasegawa, ${ }^{1 \star}$ Katsuyasu Sakurai, ${ }^{1}$ Avraham Yaron, ${ }^{2}$ John Cobb, ${ }^{3}$ and Fan Wang ${ }^{1}$ \\ ${ }^{1}$ Department of Cell Biology, Duke University Medical Center, Durham, North Carolina 27710, ${ }^{2}$ Department of Biological Chemistry, Weizmann Institute of \\ Science, Rehovot 76100, Israel, and ${ }^{3}$ Department of Biological Sciences, University of Calgary, Calgary, Alberta T2N 1N4, Canada
}

\begin{abstract}
Dorsal root ganglia (DRG) contain somatosensory neurons of diverse sensory modalities. Among these different types of sensory neurons, the molecular mechanisms that regulate the development and specification of touch neurons are the least well understood. We took a candidate approach and searched for transcription factors that are expressed in subsets of DRG neurons, and found that the transcription factor Shox 2 (short stature homeobox 2) is expressed in subpopulations of TrkB (tropomyosin-related kinase B)-and Ret-expressing neurons at neonatal stages. Since TrkB is a known marker that is selectively expressed in touch sensory neurons, we decided to examine the function of Shox2 in specifying TrkB-positive DRG neurons. Conditional deletion of Shox2 in neural crest cells (which give rise to all DRG neurons) caused a $60 \sim 65 \%$ reduction in the number of TrkB-expressing neurons. It also resulted in an increase in coexpression of TrkC in Ret-positive sensory neurons. Deletion of Shox2 in differentiating DRG neurons at later time points caused only a moderate reduction in TrkB expression. Overexpression of Shox 2 in all neural crest cells resulted in a small increase in the number of TrkBexpressing neurons. Finally, Shox 2 deletion also caused reduced touch sensory axonal innervation to layers III/IV of the spinal cord. Together, our findings identify Shox 2 as an essential but not sufficient component of the transcription programs required in neural progenitor cells for the proper specification of subsets of TrkB-expressing touch/mechanosensory neurons.
\end{abstract}

\section{Introduction}

Somatosensory neurons located in dorsal root ganglia (DRG) consist of many different types that detect diverse modalities of sensory stimuli. All DRG neurons are originated from neural crest cells (NCCs) (Ma et al., 1999; Chai et al., 2000; Szeder et al., 2003). We are interested in identifying molecular mechanisms that enable NCCs to differentiate into touch/mechanosensory neurons. Different DRG neurons have unique molecular compositions. Receptors for neurotrophic factors are among the best characterized markers for sensory neurons. It has been shown

Received Nov. 8, 2010; revised March 1, 2011; accepted March 21, 2011.

Author contributions: A.N.S., H.H., and F.W. designed research; A.N.S., H.H., K.S., and J.C. performed research; A.Y. and J.C. contributed unpublished reagents/analytic tools; A.N.S., H.H., K.S., and F.W. analyzed data; A.N.S. and F.W. wrote the paper.

This work is supported by National Institutes of Health grants from the National Institute of Dental and Craniofacial Research and a McKnight Scholar for Neuroscience Award (to F.W), as well as by the United States-Israel Binational Science Foundation (to A.Y. and F.W). In addition, J.C. is supported as an Alberta Heritage Foundation for Medical Research Scholar, and by Natural Sciences and Engineering Research Council of Canada and Canadian Institutes of Health Research Grant MOP-93562. We thank members of the Wang laboratory for helpful discussions, suggestions, and technical assistance. We thank Dr. Scott Soderling and Terry Lechler for critical reading of the manuscript. We thank the Duke Transgenic Mouse Facility for making the Rosa ${ }^{\text {CAG-STOP-Shoxz } /+}$ mice. Dr. Jeh-Ping Liu for providing the Is11-Cre mice.

${ }^{*}$ A.S. and H.H. contributed equally to this article.

The authors declare no competing financial interests.

Correspondence should be addressed to Fan Wang, Department of Cell Biology, Duke University Medical Center, Box 3709, Durham, NC 27710. E-mail: f.wang@cellbio.duke.edu.

H. Hasegawa's present address: Graduate School of Comprehensive Human Sciences, University of Tsukuba, Tsukuba, Ibaraki 305-8575, Japan.

DOI:10.1523/JNEUROSCI.5883-10.2011

Copyright $\odot 2011$ the authors $\quad 0270-6474 / 11 / 316741-09 \$ 15.00 / 0$ that TrkA (tropomyosin-related kinase A) and Ret receptors are mainly expressed in nociceptive and thermal sensory neurons (Chen et al., 2006; Kramer et al., 2006; Luo et al., 2007). TrkC is expressed primarily in proprioceptive neurons innervating the skeletal muscles (Hippenmeyer et al., 2005; Sedý et al., 2006; Inoue et al., 2007; Hasegawa and Wang, 2008). TrkB is expressed by a subpopulation of cutaneous low-threshold touch neurons (González-Martínez et al., 2004; Shimizu et al., 2007; Perez-Pinera et al., 2008). An early-born population of Ret-expressing neurons develops into rapid-adapting mechanosensory neurons (Bourane et al., 2009; Luo et al., 2009). Signaling through neurotrophic receptors is important for neuron survival, axon growth, innervation of central and peripheral targets, and proper differentiation into specialized and modality-specific sensors (Marmigère and Ernfors, 2007; da Silva and Wang, 2011).

Significant progresses have been made in elucidating the transcriptional programs specifying nociceptive and proprioceptive neurons. For example, the transcription factor Runx 1 is essential for differentiation and diversification of nociceptive neurons into peptidergic and nonpeptidergic lineages (Chen et al., 2006; Kramer et al., 2006; Marmigère and Ernfors, 2007; Inoue et al., 2008), whereas Runx3 and Er81 are important for the specification of TrkC-expressing proprioceptive sensory neurons (Levanon et al., 2001; Hippenmeyer et al., 2005; Kramer et al., 2006; Inoue et al., 2007). Recently, MafA was shown to be involved in the development of Retpositive rapid-adapting mechanoreceptors (Bourane et al., 2009). However, the transcription factors that enable progen- 
itor cells to differentiate into TrkB-expressing mechanosensory neurons remain unclear.

We searched for transcription factors expressed in a subset of DRG neurons and found the gene encoding Shox2 (short stature homeobox 2), a homeobox transcription factor, is dynamically expressed during DRG development. The mouse Shox2 gene displays 99 and $73 \%$ similarity to human Shox 2 and Shox, respectively. Mutations in human Shox cause short stature and Leri-Weill dyschondrosteosis (Marchini et al., 2007; Binder, 2011). Mice only have the Shox 2 gene. Thus, it appears that mouse Shox 2 assumes the functions of both human Shox and Shox2. Shox 2 mutant mice show defects in bone, heart, and palate development (Yu et al., 2005; Cobb et al., 2006; Blaschke et al., 2007). However, the role of Shox2 in neuronal development has not been examined. Here we performed loss- and gain-of-function analyses to determine the role of Shox 2 in DRG development. We discovered that Shox2 is important for the development of TrkB-expressing mechanosensory neurons.

\section{Materials and Methods}

Mice. Shox2 $2^{\text {flox/flox }}$ (Cobb et al., 2006), Wnt1-Cre (Danielian et al., 1998), Advillin ${ }^{\mathrm{Cre} /+}$ (Zhou et al., 2010), Isl1 ${ }^{\mathrm{Cre} /+}$ (Srinivas et al., 2001; Yang et al., 2006), and Advillin ${ }^{P L A P /+}$ (Hasegawa et al., 2007) mice have all been previously described. Rosa ${ }^{C A G-S T O P-S h o x 2 /+}$ mouse was generated by inserting a cassette of "chicken $\beta$ Actin promoter-LoxP-neo-polyA-LoxP-Shox2polyA" into the Rosa26locus via homologous recombination. Genotyping of the Rosa ${ }^{\text {CAG-STOP-Shox2/+ }}$ mice was performed by PCR. PCR primers were designed as follows: Rosa/01, 5-CACTTGCTCTCCCAAAGTCG-3; Rosa/02, 5-TAGTCTAACTCGCGACACTG-3; and CAG/02, 5-GTTATGTAACGCGGAACTCC-3. The wild-type allele produces a $560 \mathrm{bp}$ fragment with Rosa/01 and Rosa/02 primers, whereas the knock-in allele results in a $300 \mathrm{bp}$ fragment with Rosa/01 and CAG/02 primers. Furthermore, primers were designed to specifically detect the Shox 2 cDNA in the Rosa ${ }^{C A G-S T O P-S h o x 2}$ allele: RShox2/01, 5-GTGTCCCCTGAACTGAAGGA-3; and RShox2/02, 5-GCCTGAACCTGAAAGGACAA-3. The knock-in allele produces a 400 bp fragment using the RShox2/01 and RShox2/02 primers. All experiments were conducted according to protocols approved by The Duke University Institutional Animal Care and Use Committee.

In situ hybridization. The mouse cDNA fragments of the neurotrophic receptors and Shox 2 were amplified by PCR with the antisense primers containing the $\mathrm{T} 7$ promoter sequence. In vitro transcription was then performed from the PCR-amplified template using T7 RNA polymerase (Roche) with Digoxigenin-UTP (Roche) for the synthesis of the antisense probes. In situ hybridization was performed according to standard methods (Hodge et al., 2007). Fluorescent two-color in situ hybridization was performed according to standard methods (Hasegawa and Wang, 2008).

Immunostaining. Immunostaining was performed according to standard methods (Hodge et al., 2007). The following antibodies were used: Alexa Fluor 488-conjugated IB4 (Invitrogen), anti-Caspase 3 (active) (1:1000; R\&D Systems), anti-CGRP (calcitonin gene-related peptide) antibody (1:2000; Millipore Bioscience Research Reagents/Invitrogen), antiPGP9.5 antibody (UltraClone), anti-vGluT1 antibody (1:1000; Millipore), Alexa 488-labeled anti-rabbit IgG (1:400; Invitrogen), Alexa 488-labeled anti-guinea pig IgG (1:400; Invitrogen), and Cy3-labeled anti-rabbit IgG (1:400, Jackson Laboratories).

Alkaline phosphatase staining. Alkaline phosphatase staining was performed according to standard methods (Hasegawa et al., 2007).

Quantification methods. For every developmental stage, at least three embryos/pups from two to three different litters were analyzed. In situ (or immuno) signal-positive DRG neurons were counted from randomly selected sections. For counting TrkA- or Ret-positive neurons, $N=20$ randomly selected sections from each animal are counted; for counting Shox2-, TrkC-, TrkB-, or activated caspase-3-positive neurons, $N=$ $40 \sim 50$ randomly selected sections from each animal are counted; and for counting MafA-, Runx3-, or parvalbumin-positive neurons, $N=$ $30 \sim 35$ randomly selected sections from each animal are counted. On each section, the area of the DRG was measured using MetaMorph soft-
A Shox2
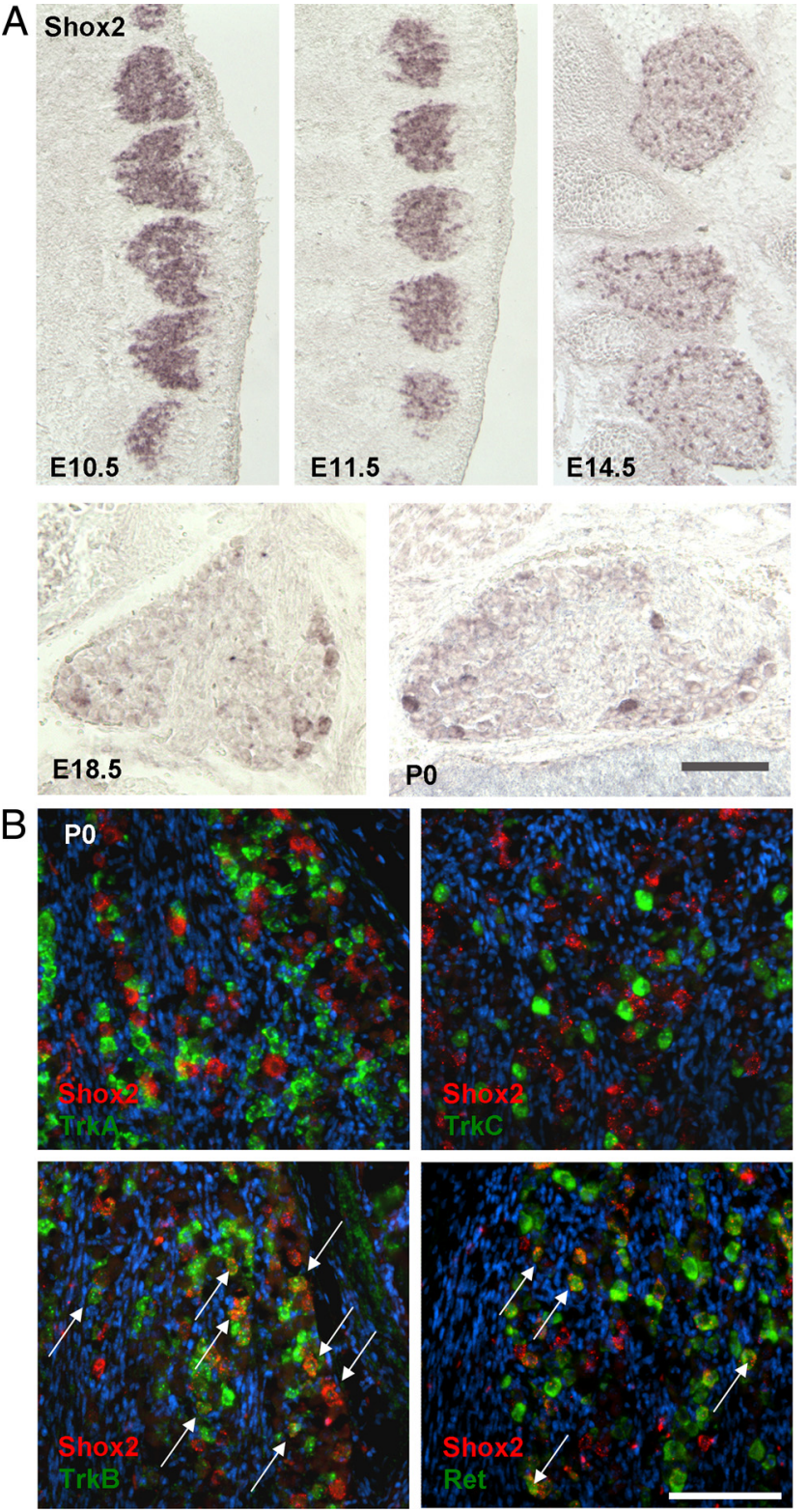

Figure 1. Shox2 expression in the developing DRG. $A$, In situ hybridization experiments show that at E10.5 and E11.5 Shox2 is expressed throughout the entire DRG; at E14.5, Shox2 expression begins to downregulate in subsets of DRG neurons; and by E18.5 and PO, Shox2 is only present in a small number of DRG neurons. $\boldsymbol{B}$, Two-color in situ hybridization with probes for Shox2 (red) and different receptors (TrkA, TrkB, TrkC, and Ret) (green). Arrows indicate cell bodies in the ganglia showing colocalization of Shox2 with either TrkB or Ret. Note that not all TrkB- or Ret-positive cell bodies have Shox2 expression at P0. Scale bar, $100 \mu \mathrm{m}$.

ware. The number of cells per unit area is then calculated and averaged over all embryos/animals. $p$ values were calculated using Student's $t$ test. Placenta alkaline phosphatase (PLAP) staining intensity (from 50 randomly selected sections of animals of two different litters), and vGluT1 staining intensities and areas (from 60 randomly selected sections of animals of two different litters) were measured using MetaMorph software and were set to artificial units. $p$ values were calculated with Student's $t$ test.

\section{Results}

Shox 2 expression pattern in the developing mouse DRG In situ hybridization was performed to examine the expression of Shox2 in the developing mouse DRG. At early stages beginning at embryonic day 10.5 (E10.5), Shox2 is expressed throughout the 
A

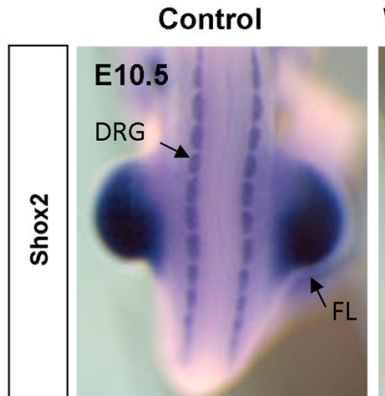

E14.5

B

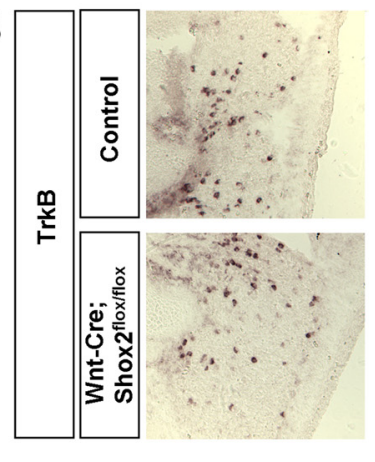

C

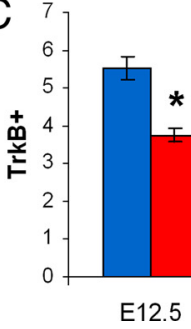

E16.5

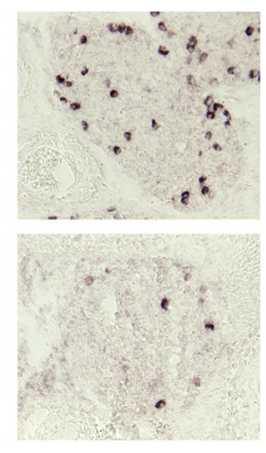

Wht-Cre; Shox $2^{\text {floxfflox }}$

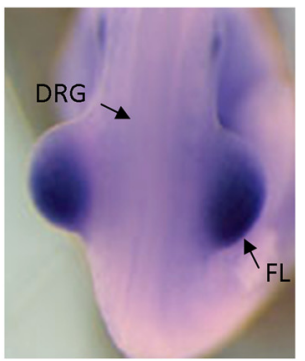

E18.5

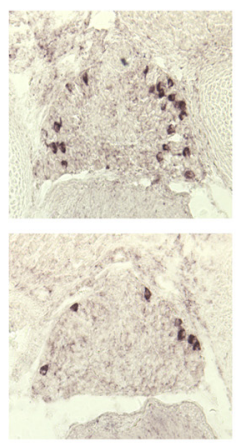

Figure 2. Reductions in the number of TrkB-expressing DRG neurons in Wnt1-Cre; Shox ${ }^{\text {floxfflox }}$ embryos. A, In situ hybridization reveals the absence of Shox2 expression in DRGs of Wnt1-Cre; Shox $2^{\text {floxfflox }}$ mice at E10.5. B, Representative images of TrkB expression in control and Shox2-deleted DRGs at E14.5, E16.5, E18.5, and P0. C, Quantifications of the numbers of TrkBexpressing DRG neurons per unit area in control and Wnt1-Cre; Shox $2^{\text {flox/flox }}$ embryos. ${ }^{*} p<0.001$. Error bars represent \pm SEM. Scale bar, $100 \mu \mathrm{m}$. FL, Forelimb.

ganglion (Fig. 1A). By E14.5, its expression begins to downregulate in the majority of sensory neurons (Fig. $1 A$ ). This downregulation continues after E14.5, and by E18.5 only a small population of DRG neurons retains stable expression of Shox2, which persist into adulthood (data not shown) (Fig. $1 A$ ). The dynamic expression pattern of Shox2 led us to hypothesize that Shox 2 is involved in the specification and development of subtypes of DRG neurons. To test this, we performed fluorescent two-color in situ hybridization experiments to examine the potential coexpression of Shox 2 with Trks or Ret receptors (which are markers for different somatosensory lineages). We observed that at postnatal day 0 (P0), Shox 2 colocalizes with subsets of TrkB- or Retexpressing neurons and is absent from the TrkA- and TrkCexpressing cells (Fig. $1 B$ ). Upon quantification, we found that $65 \%$ of Shox2-positive cells colocalize with $65 \%$ of $\operatorname{TrkB}$ neurons, and the remaining 35\% of Shox2-expressing cells colocalizes with a small number of Ret-positive DRG neurons. Since $\operatorname{TrkB}$ has been shown to be a marker for subsets of mechanosensory neurons, and Ret is expressed in some of the rapid-adapting mechanosensory neurons in addition to nociceptive neurons, the coexpression results suggest that Shox2 may be involved in the differentiation of NCCs into mechanosensory neurons.
PO

Control

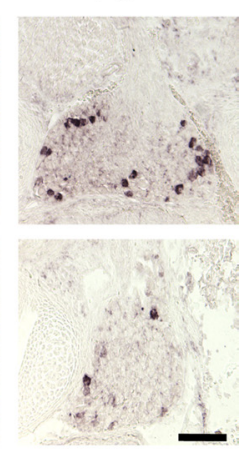

Significant reduction in the number of TrkB-expressing DRG neurons in Wnt1-Cre; Shox $2^{\text {floxfllox }}$ mouse

To examine the function of Shox 2 in DRG neuron development, we used Wnt1-Cre (Danielian et al., 1998) to conditionally delete the Shox2 gene in all neural crestderived cells including DRG neurons. We crossed Wnt1-Cre mice with Shox $2^{\text {flox/flox }}$ mice (Danielian et al., 1998; Cobb et al., 2006) to obtain conditional mutant Wnt1Cre; Shox $2^{\text {flox/flox }}$ (as well as control Wnt1Cre; Shox $2^{\text {flox/+ }}$ ) embryos and neonates. Figure $2 A$ shows the absence of Shox 2 expression in DRGs from Shox 2 mutant embryo at E10.5. In our hands, all Shox2 mutant mice die within $2 \mathrm{~d}$ after birth due to an anterior cleft palate defect (data not shown), which limited our characterization of the role of Shox 2 to embryonic and neonatal stages.

Using in situ hybridization, we examined the expression of Trks and Ret receptors in developing DRG at different stages in the mutant and control embryos. There is no observable difference in the number of TrkA- or Ret-positive cells at all time points examined, suggesting that Shox2 does not play a major role in the development of nociceptive lineage (Fig. 3C,D). In contrast, we observed a significant decrease in the number of TrkB-expressing cells in the Shox2-deleted DRG compared with controls at all time points examined (Fig. $2 B, C$ ). On average, there is a $60 \sim$ 65\% loss of TrkB-expressing DRG neurons at stages after E16.5 (Fig. 2C), which is consistent with the fact that $65 \%$ of TrkB neurons express Shox2. Finally, the proprioceptive lineage marker $\operatorname{Trk} C$ showed a mild increase in the Shox2-deleted DRG at perinatal stages starting after E18.5 (Fig. 3A,B). The detailed method used for quantifying the numbers of different types of DRG neurons in these and subsequent results is described in Materials and Methods.

Previous studies have shown that the transcription factors MafA and Runx3 are involved in the development of the Ret-positive mechanosensory neurons and TrkC-positive proprioceptive neurons, respectively (Kramer et al., 2006; Inoue et al., 2007; Bourane et al., 2009). We used in situ hybridization to examine the expression of both of these transcription factors in mutant and control mice. We found that there was no difference in the number of DRG neurons expressing either MafA or Runx3 in the Shox2-deleted versus control DRG at P0 or P2 (Figure $3 E-G$ ). The result suggests that Shox 2 does not regulate MafA or Runx3 expression and, by extension, probably does not play a major role in the development/specification of Ret-positive rapid-adapting mechanosensory neurons or TrkC-expressing proprioceptive neurons.

Loss of TrkB-expressing DRG neurons in Wnt1-Cre; Shox $2^{\text {flox/flox }}$ mouse is not caused by elevated apoptosis

We next investigated whether apoptosis could account for the observed loss of TrkB-expressing neurons in Wnt1-Cre; Shox $2^{\text {flox/flox }}$ DRG. We used anti-activated caspase-3 antibody to detect cell 
death and found no statistically significant difference in the number of apoptotic cells in Shox2-deleted versus control DRG at all time points examined (Fig. $4 A, B$ ). Note that both Shox2-deficient and control DRGs show increased numbers of caspase-3-positive cells at E14.5 (Fig. 4B), a time point of naturally occurring cell death of developing sensory neurons, as shown previously (Raff et al., 1993; White et al., 1998). Thus, the loss of TrkB expression in Shox2 mutant mice is not likely due to apoptosis of sensory neurons.

TrkC coexpression in subsets of TrkB- or Ret-positive sensory neurons in Wnt1-Cre; Shox $2^{\text {flox/flox }}$ mouse It is known that during early DRG neurogenesis, the transient population of TrkC/ TrkB-double-positive progenitor neurons later differentiate into TrkB-single-positive or Ret-single-positive mechanosensory neurons, or TrkC-single-positive proprioceptive neurons (Kramer et al., 2006; Marmigère and Ernfors, 2007). However, there appears to be a small percentage of sensory neurons that maintains coexpression of TrkB/TrkC or Ret/TrkC. We thus examined the coexpression of TrkC in the remaining TrkBexpressing, as well as in Ret-expressing, DRG neurons in Shox2 mutant mice.

We first performed fluorescent twocolor in situ hybridization to detect TrkB and $\operatorname{Trk} C \mathrm{mRNA}$ simultaneously. In control DRGs at E14.5, $\sim 33 \%$ of TrkB-positive neurons also express TrkC. By E16.5, $<10 \%$ of TrkB cells still express TrkC in wild-type DRGs. This number is further reduced during postnatal development (Fig. 5A). In Wnt1-Cre; Shox $2^{\text {flox/flox }}$ DRGs, there is an apparent increase in the relative percentage of TrkB/TrkC-double-positive cells. However, when we quantified the actual average numbers of $\operatorname{TrkB} / \operatorname{TrkC}$-double-positive DRG neurons per unit area, there is no statistically significant difference between control and Shox2 mutant DRGs (Fig. $5 B$ ). This result suggests that in the wildtype mouse TrkB/TrkC-double-positive mechanosensory neurons normally belong to the 35\% TrkB-positive but Shox2negative populations, and thus their number is unaffected by Shox 2 deletion.

Since Shox2 is also expressed in a subset of Ret-positive neurons (Fig. $1 B$ ), we also examined coexpression of TrkC in Ret-expressing sensory neurons. Again, using two-color in situ hybridization, we found that there is a small percentage of Ret-positive cells also expressing $\operatorname{Trk} C$ at perinatal stages in both control and Shox 2 mutant DRGs. Interestingly, the average number of Ret/TrkC-double-positive neurons per unit area is increased in the mutant (Fig. 5C,D). This result is consistent with the observed increase in the total number of $\operatorname{TrkC}$ expressing DRG neurons and suggests that normally the function
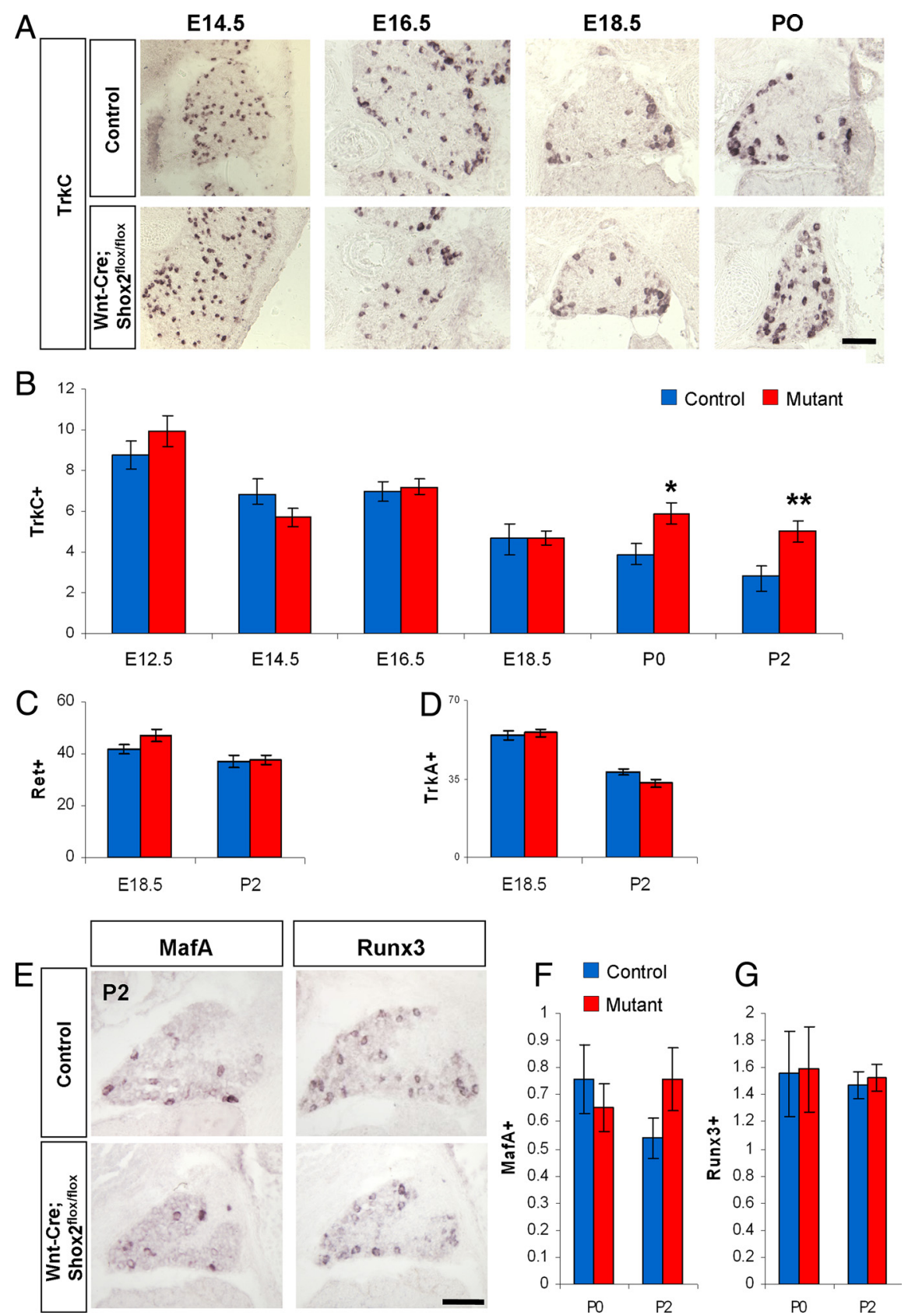

Figure 3. Increases in the number of TrkC-expressing DRG neurons in Wnt1-Cre; Shox $2^{\text {flox/flox }}$ mice at perinatal stages. $\boldsymbol{A}$, Representative images of TrkC expression in control and Shox2-deleted DRG at E14.5, E16.5, E18.5, and P0. B, Quantifications of the numbers of TrkC-expressing DRG neurons per unit area in control and Wnt1-Cre; Shox $2^{\text {flox/flox }}$ embryos at six different stages. Note that there is an increase in the number of TrkC-expressing neurons in the mutant at $\mathrm{PO}\left({ }^{*} p<0.005\right)$ and $\mathrm{P} 2\left({ }^{* *} p<0.001\right) . \mathbf{C}, \boldsymbol{D}$, Quantification of the number of Ret-and TrkA-expressing neurons in control and Wnt1-Cre; Shox $2^{\text {flox/flox }}$ mice atE18.5 and P2.Scale bar, $100 \mu \mathrm{m}$. E, Representative images of MafA and Runx3 expression in control and Shox2-deleted DRGs at P2. F, G, Quantifications show no significant differences in the numbers of cells expressing MafA or Runx3 per unit area between the control and Shox2-deleted DRGs at P0 and P2. Error bars represent \pm SEM.

of Shox2 in Ret-positive neurons may be to suppress TrkC expression.

To examine whether any of the Ret/TrkC-double-positive cells in Shox2-deleted DRGs differentiate toward a proprioceptive neuron fate, we performed two-color in situ hybridization to detect Ret and Parvalbumin ( $P V)$ simultaneously. Parvalbumin is a known marker for TrkC expressing proprioceptive sensory neurons (Arber et al., 2000). Ret/PV-double-positive cells are rarely seen in either control or Shox2-mutant DRG, and there is no statistically significant difference in the total number of $P V$ - 

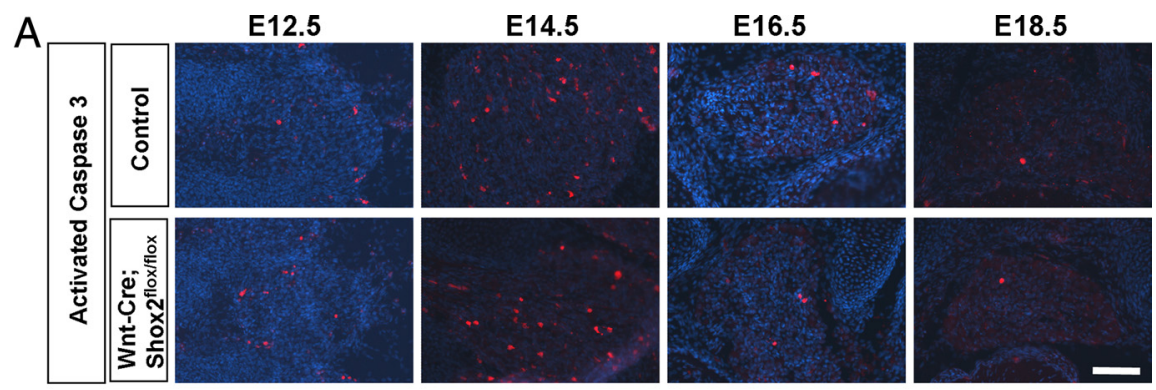

\section{B}

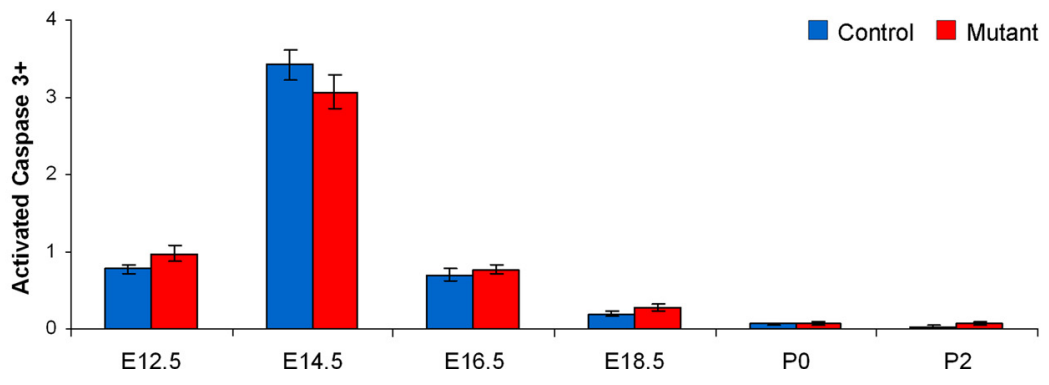

Figure 4. Apoptosis is normal in Wnt1-Cre; Shox $2^{\text {flox/flox }}$ DRGs. A, Representative images of immunostaining with antiactivated-caspase-3 in control and Shox2-deleted DRGs at E12.5, E14.5, E16.5, and E18.5. B, Quantifications show no significant differences in the amount of apoptotic cells between control and Shox2-deleted DRGs. Note that at E14.5, a time point of naturally occurring cell death, there is an increase in activated-caspsase-3-positive cells in both control and mutant DRGs. Error bars represent \pm SEM. Scale bar, $100 \mu \mathrm{m}$.

positive neurons between control and mutant mice (data not shown) (Fig. 5E). This result suggests that the increased number of Ret/TrkC-double-positive neurons in Shox2-mutant DRG do not appear to be proprioceptive neurons. To determine whether any of the Ret/TrkC-double-positive neurons belong to the late-born Ret-positive nociceptive neurons, we performed two-color in situ using $M r g D$ and $\operatorname{TrkC}$ probes. MrgD is expressed exclusively in Ret/ Runx1-expressing nonpeptidergic nociceptive neurons (Liu et al., 2008). We did not find any MrgD/TrkC-double-positive neurons in either control or Shox2-mutant mice (Fig. $5 F$ ). Thus, by exclusion, the increased Ret/TrkC-double-positive neurons in the Shox $2 \mathrm{mu}-$ tant are mechanosensory neurons.

Together, Shox 2 deletion resulted in a significant loss of TrkB expression and a mild increase of $\operatorname{TrkC}$ coexpression in small number of Ret-positive mechanosensory neurons. These data suggest that Shox2 is essential for the proper expression of neurotrophic receptors during the differentiation of mechanosensory neurons.

\section{Developmental time-dependent requirement of Shox 2 for proper TrkB expression in DRG neurons}

Previous studies have found time-dependent roles of certain transcription factors [ETS genes, Islet1 (Isl1)] in DRG neuron development (Hippenmeyer et al., 2005; Sun et al., 2008). We therefore wanted to determine the time window when Shox 2 is required for the development of a subset of TrkB-expressing sensory neurons. We used $A v i^{C r e /+}$ (Zhou et al., 2010) to delete the Shox2 gene at later stages by generating Avil ${ }^{\mathrm{Cre} /+}$; Shox $2^{\text {flox/flox }}$ mice. Advillin is a gene whose expression is largely restricted to peripheral sensory neurons. Advillin is weakly expressed in a few DRG neurons at E12.5 and reaches peak expression at E16.5 (Hasegawa et al., 2007; Zhou et al., 2010; da Silva et al., 2011). Avil ${ }^{\mathrm{Cre} /+}$ mediated deletion of Shox 2 is completed at E18.5 (Fig. 6A).

The Avil ${ }^{\mathrm{Cre} /+}$; Shox $2^{\text {flox/flox }}$ mice are viable and fertile, and appear normal. Using in situ hybridization, we found that the number of TrkB-positive cells is only moderately decreased in these mutants compared with the controls (Fig. 6B, C). Furthermore, were crossed with Wnt1-Cre to obtain Wnt1-Cre; RosaCAG-STOP-Shox2/+ mice. In situ hybridization confirmed the overexpression of Shox 2 mRNA in all DRG cells (Fig. 7A). Wnt1-Cre; Rosa CAG-STOP-Shox2/+ mice die immediately at birth, due to a completely cleft palate (data not shown). We examined the expression of Trks and Ret in these mice at E18.5 and P0 stages. Upon quantification, we found a $20 \%$ increase in the number of TrkB-positive neurons in DRGs from Shox2 overexpression embryos (Fig. $7 B, C$ ). However, no apparent changes in $\operatorname{Trk} A, \operatorname{Trk} C$, and Ret expression were detected in these mice compared with the controls (Fig. 7D-F). Thus, although Shox2 is necessary for inducing and/or maintaining $\operatorname{TrkB}$ expression in subsets of mechanosensory neurons, it is not sufficient to induce $\operatorname{Trk} B$ or suppress $\operatorname{Trk} C$ expression in all DRG neurons.

\section{Defects in mechanosensory neuron central innervations in Shox2-deficient mice}

Finally, we examined the consequences of loss of Shox 2 on the peripheral and central axonal projections of mechanosensory DRG neurons. To visualize the axonal projections, we used the Avil ${ }^{\text {PLAP/+ }}$ mice in which human PLAP is inserted into the Advillin locus (Hasegawa et al., 2007). We crossed Wnt1-Cre; Shox $2^{f l o x /+}$ males with $A v i l^{P L A P /+}$; Shox $2^{\text {flox/flox }}$ females to generate Avil ${ }^{P L A P /+}$; Wht1-Cre; Shox $2^{\text {flox/flox }}$ mutant mice and their littermate controls. Since no mutant mice survive past P2, we examined axonal projection at E18.5, P0, and P2. At these stages, the peripheral axons have reached their targets, but have not yet fully differentiated into specialized sensory endings (Albuerne et al., 2000; Hasegawa et al., 2007), thereby preventing us from definitively determining the exact morphological subtypes of neurons that are affected by Shox 2 deletion. Using PLAP staining and antiPGP9.5 staining, we did not detect any apparent differences in the general peripheral sensory projections into the hairy or the glabrous skin (data not shown).

However, PLAP staining on spinal cord sections from control or Avil ${ }^{\text {PLAP/+ }}$; Wht1-Cre; Shox $2^{\text {flox/flox }}$ mutant mice revealed that 
the Shox2-deleted DRG neurons showed reduced central axonal innervation to layers III/IV of the spinal cord compared with the control (Fig. 8). Note that layer III/IV stained strongly for PLAP in the control (Fig. $8 \mathrm{~A}$, arrow), but the corresponding region in the Wnt1-Cre; Shox $2^{\text {flox/flox }}$ mutant spinal cord stained much weaker (Fig. $8 A$ ). On average, there is a $10 \%$ reduction in the PLAP staining intensity in Shox2 mutant $(p<0.001)$. Since layers III/IV receive inputs from mechanosensory neurons, including TrkB- and Ret-expressing touch neurons, this observation suggests that Shox 2 deficiency causes central innervation defects in subsets of mechanosensory neurons. Note that the reduced PLAP staining in layer III/IV was not due to changes in the expression of Advillin locus as PLAP staining in the DRG cell bodies and peripheral axons was equally intense, and in situ hybridization showed a similar level of Advillin expression in both control and Shox2-deleted DRGs (data not shown).

To confirm the central axon innervation defects with an independent method, we also used Isl1 ${ }^{\text {cre/+ }}$ (Srinivas et al., 2001) to conditionally delete Shox2. Isl1 is expressed in all sensory neurons beginning at E10; thus, in these mice Shox2 is deleted at early stages of DRG neuron differentiation. In Isl1 ${ }^{\text {cre/+ }}$; Shox $2^{\text {flox/flox }}$ mice, we observed a $53 \%$ reduction in the number of TrkB-expressing cells, only slightly less than what we observed in Wnt1-Cre; Shox $2^{\text {flox/flox }}$ mice $(p<0.001$; data not shown). We used anti-vGlut1 staining to specifically visualize mechanosensory afferent termini (whereas Avil ${ }^{\text {PLAP/+ }}$ labels all axons including nociceptive afferents). The average vGluT1 staining intensity in layer III/IV showed an $11 \%$ reduction in Isl1 ${ }^{\text {cre/+}} ;$ Shox $2^{\text {flox/flox }}$ dorsal spinal cord compared with that in controls (Fig. $8 \mathrm{~B}$ ) $(p<0.002)$. As a control, the vGLUT staining signals in DRG neuronal cell bodies were indistinguishable between control and Shox 2 mutant mouse (Fig. $8 B$, insets). In addition, the average area covered by vGluT1-positive mechanosensory axons in dorsal horn spinal cord is also reduced by $\sim 20 \%$ in $I s l 1^{\text {cre/+ }}$; Shox $2^{\text {flox/flox }}$ mice (Fig. $8 B)(p<0.001)$. Not surprisingly, nociceptive innervation to the dorsal horn as revealed by anti-CGRP and IB4 staining (to visualize peptidergic and nonpeptidergic nociceptive central axonal projections, respectively) was unchanged in Shox 2 mutant mice (Fig. 8C). Together, our study uncovered an important requirement for the transcription factor Shox 2 for the proper development, differentiation, and central innervation of a subset of TrkB-expressing mouse mechanosensory neurons.

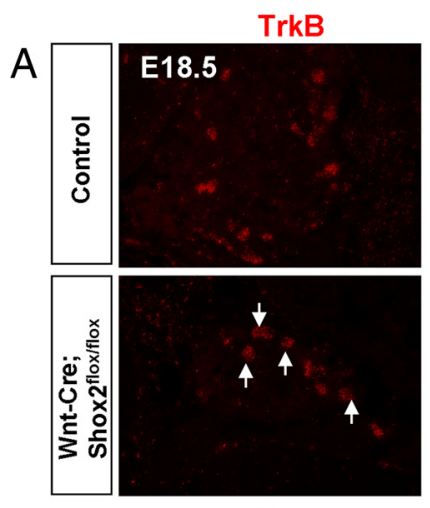

Ret

B
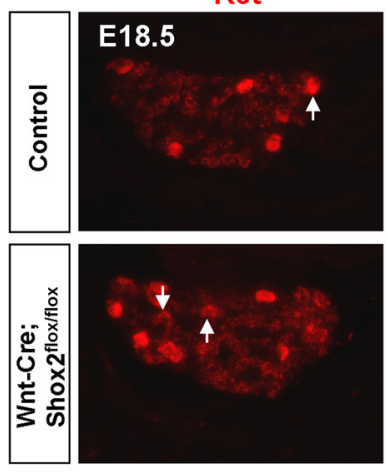

C
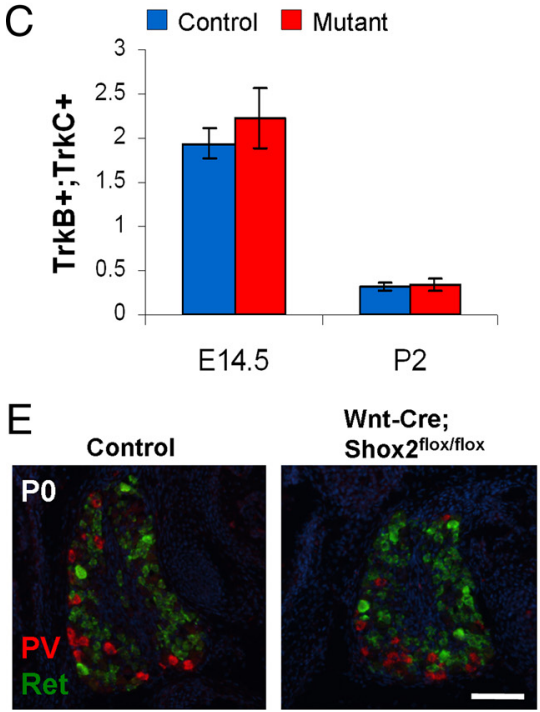

TrkC
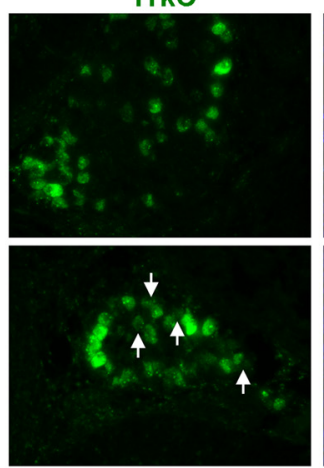

TrkC
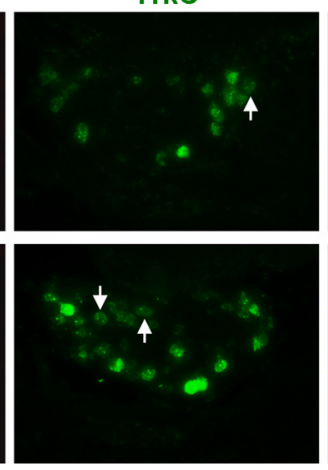

D

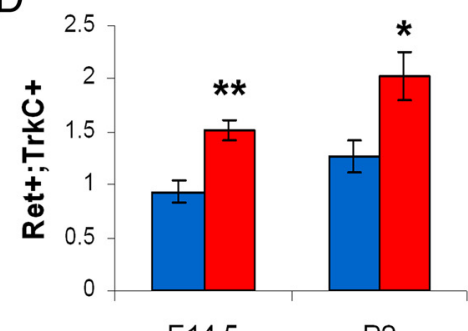

E14.5
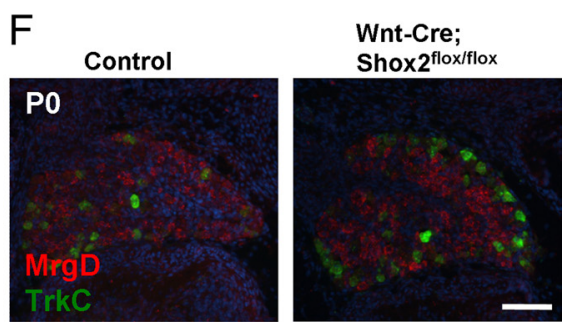

Figure 5. Increased coexpression of Ret and TrkC in DRG neurons in Wnt1-Cre; Shox $2^{\text {flox/flox }}$ mice. A, Representative results of two-color in situ hybridization using TrkB (red) and TrkC (green) probes at E18.5. Arrows indicate neurons in the DRGs that are positive for both receptors. $\boldsymbol{B}$, Representative results of two-color in situ hybridization using Ret (red) and TrkC (green) probes at E18.5. Arrows indicate cell bodies in the DRGs that are positive for both receptors. C, Quantification of the average number (per unit area) of TrkB/TrkC-double-positive neurons revealed no significant difference between the control and Shox2-deleted mice. $\boldsymbol{D}$, Quantification of the average number (per unit area) of Ret/TrkC-double-positive neurons showed a significant increase in the Shox2-deleted versus control DRGs. E, Representative images of two-color in situ hybridization results with Parvalbumin (red) and Ret (green) probes at PO.F, Representative images of two-color in situ hybridization results with MrgD (red) and TrkC (green) probes at $\mathrm{P} 0{ }^{*} p<0.01,{ }^{* *} p<0.001$. Error bars represent \pm SEM. Scale bars, $100 \mu \mathrm{m}$.

\section{Discussion}

In the mammalian peripheral somatosensory system, mechanosensory and proprioceptive lineages arise from the same progenitor populations, through the first wave of neurogenesis from the precursor NCCs that migrate into the site of the future DRGs at E9 (Fode et al., 1998; Ma et al., 1999). The initially TrkC/TrkBdouble-positive progenitor neurons eventually differentiate into 
A

P2

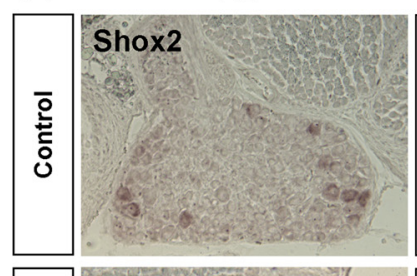

B

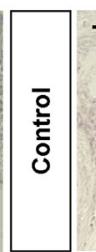

E18.5

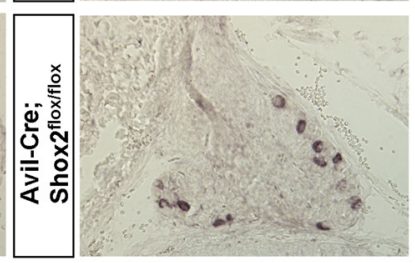

$\mathrm{E}$

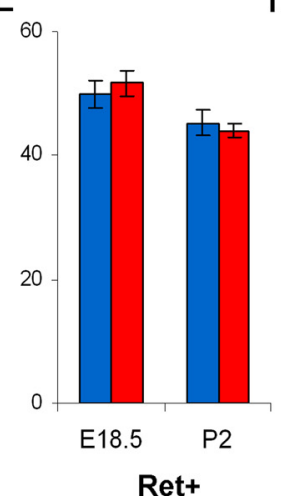

P2
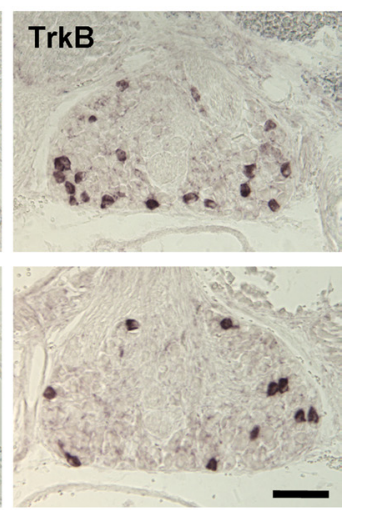

F

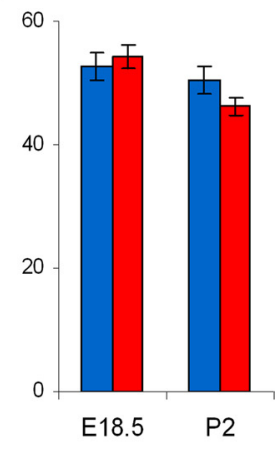

TrkA+

Figure 6. Mild reduction in the number of TrkB-expressing cells in $A v i i^{\left(r^{\prime} /+\right.}$; Shox $2^{\text {flox/flox }}$ mice. $A$, In situ hybridization confirms the loss of Shox2 expression in the DRGs from Avil ${ }^{(r e /+}$; Shox $2^{f l o x} / f$ lox mice. $B$, Representative images of TrkB expression in control and Avil(re/+ ; Shox2 ${ }^{f l o x f f l o x}$ mice at E18.5 and P2. C $-\boldsymbol{F}$, Quantification of the numbers of TrkB- (C), TrkC- (D), Ret- (E), and TrkAexpressing $(\boldsymbol{F})$ DRG neurons per unit area in control and Avil ${ }^{\text {(re/ }+}$; Shox $2^{\text {flox fflox }}$ mice at E18.5 and P2. ${ }^{*} p<0.001$. Error bars represent \pm SEM. Scale bar, $100 \mu \mathrm{m}$.

TrkC-single-positive proprioceptive neurons, as well as TrkB- or Ret-single-positive touch sensory neurons, although a very small number of mechanosensory neurons are TrkB/TrkC or Ret/TrkC double positive. Previously, the molecular mechanisms regulating the specification of TrkB-expressing mechanosensory neuron lineage are unknown. In this study, we discovered that Shox2 is an essential, although not sufficient, component required for the proper development of a subpopulation of TrkB-positive DRG neurons.

Wnt1-Cre-mediated deletion of Shox2 in NCCs results in a $60-65 \%$ reduction in the number of TrkB-expressing DRG neurons at stages after E16.5. Shox2 deletion also caused a small increased in TrkC/Ret-double-positive neurons at later stages. These findings suggest that Shox 2 is important for ensuring TrkB expression and may contribute to TrkC repression in Retexpressing touch sensory neurons, although at present we do not yet know whether such effects of Shox2 are direct or indirect.

Later deletion of Shox 2 using Avil ${ }^{\mathrm{Cre} /+}$ resulted in only a moderate decrease in TrkB-positive neurons than that observed in Wnt1-Cre-mediated deletion mice, suggesting that Shox 2 is required in progenitor and early-born neurons to promote their differentiation into TrkB-expressing touch neurons. The onset of Advillin expression occurs at E12.5 and reaches a maximum at E16.5. It is likely that only those neurons that express Cre at early stages (E12.5) are affected and lose TrkB expression, whereas those that express Cre after E12.5 are not affected by Shox2 deletion. Perhaps once the stable high-level expression of $\operatorname{TrkB}$ is established, Shox 2 is no longer needed for the maintenance of TrkB expression. In our gain-of-function studies, overexpression of Shox 2 in all NCC progenitor cells only mildly increased the number of TrkB-positive cells, but had no effects on other Trks or Ret receptor expressions, including TrkC. Together, Shox 2 is necessary for inducing or maintaining TrkB expression in a subpopulation of mechanosensory neurons, but alone is not sufficient to induce TrkB expression in nonmechanosensory neurons. A model summarizing previous and current finding related to proprioceptive and mechanosensory neuron specification is shown in Figure 9.

At present, we do not know the downstream targets of Shox2, nor do we know whether Shox2 only regulates Trk receptor expression or whether it also regulates other genes involved in other aspects of the touch/mechanosensory neuronal development. In other sensory lineages, the transcription factors Runx3 and Runx1 control all of the gene expression programs relevant to proprioceptive or nociceptive sensory neurons development and differentiation, respectively (Chen et al., 2006; Kramer et al., 2006; Inoue et al., 2008). On the other hand, the transcription factor Klf7 is required only for TrkA gene expression by binding to an enhancer element in the TrkA promoter. The loss of Klf7 leads to increased apoptosis of nociceptive sensory neurons. However, Klf7 did not appear to regulate other aspects of the differentiation program of TrkA-positive neurons (Lei et al., 2005). Future work is needed to determine the transcription targets of Shox 2 .

In Shox2-deficient mice, the central afferent innervations from mechanosensory neurons to layers III/IV in the spinal cord are reduced. Again, this could be a direct consequence of failed differentiation of a subset of TrkB-expressing touch neurons, or a secondary effect due to the loss of TrkB expression. Unlike the wealth of marker genes known for proprioceptive or nociceptive neurons, a very limited number of molecular markers are known to specifically label TrkB-expressing mechanosensory neurons. We, therefore, could not examine other molecular aspects of mechanosensory neuron development and differentiation in Shox 2 mutant mice. Nonetheless, Shox 2 is the first transcription factor discovered that affects TrkB expression in mechanosensory DRG neurons.

\section{References}

Albuerne M, De Lavallina J, Esteban I, Naves FJ, Silos-Santiago I, Vega JA (2000) Development of Meissner-like and Pacinian sensory corpuscles in the mouse demonstrated with specific markers for corpuscular constituents. Anat Rec 258:235-242.

Arber S, Ladle DR, Lin JH, Frank E, Jessell TM (2000) ETS gene Er81 controls the formation of functional connections between group Ia sensory afferents and motor neurons. Cell 101:485-498.

Binder G (2011) Short stature due to SHOX deficiency: genotype, phenotype, and therapy. Horm Res Paediatr 75:81-89.

Blaschke RJ, Hahurij ND, Kuijper S, Just S, Wisse LJ, Deissler K, Maxelon T, Anastassiadis K, Spitzer J, Hardt SE, Schöler H, Feitsma H, Rottbauer W, Blum M, Meijlink F, Rappold G, Gittenberger-de Groot AC (2007) Targeted mutation reveals essential functions of the homeodomain transcription 
factor Shox2 in sinoatrial and pacemaking development. Circulation 115:1830-1838.

Bourane S, Garces A, Venteo S, Pattyn A, Hubert T, Fichard A, Puech S, Boukhaddaoui H, Baudet C, Takahashi S, Valmier J, Carroll P (2009) Lowthreshold mechanoreceptor subtypes selectively express MafA and are specified by Ret signaling. Neuron 64:857-870.

Chai Y, Jiang X, Ito Y, Bringas P Jr, Han J, Rowitch DH, Soriano P, McMahon AP, Sucov HM (2000) Fate of the mammalian cranial neural crest during tooth and mandibular morphogenesis. Development 127:1671-1679.

Chen CL, Broom DC, Liu Y, de Nooij JC, Li Z, Cen C, Samad OA, Jessell TM, Woolf CJ, Ma Q (2006) Runx1 determines nociceptive sensory neuron phenotype and is required for thermal and neuropathic pain. Neuron 49:365-377.

Cobb J, Dierich A, Huss-Garcia Y, Duboule D (2006) A mouse model for human shortstature syndromes identifies Shox2 as an upstream regulator of Runx2 during long-bone development. Proc Natl Acad Sci U S A 103:4511-4515.

da Silva S, Wang F (2011) Retrograde neural circuit specification by target-derived neurotrophins and growth factors. Curr Opin Neurobiol 21:61-67.

da Silva S, Hasegawa H, Scott A, Zhou X, Wagner AK, Han BX, Wang F (2011) Proper formation of whisker barrelettes requires periphery-derived Smad4-dependent TGF\{beta\} signaling. Proc Natl Acad Sci U S A 108:3395-3400.

Danielian PS, Muccino D, Rowitch DH, Michael SK, McMahon AP (1998) Modification of gene activity in mouse embryos in utero by a tamoxifen-inducible form of Cre recombinase. Curr Biol 8:1323-1326.

Fode C, Gradwohl G, Morin X, Dierich A, LeMeur M, Goridis C, Guillemot F (1998) The bHLH protein NEUROGENIN 2 is a determination factor for epibranchial placode-derived sensory neurons. Neuron 20:483-494.

González-Martínez T, Germanà GP, Monjil DF, Silos-Santiago I, de Carlos F, Germanà G, Cobo J, Vega JA (2004) Absence of Meissner corpuscles in the digital pads of mice lacking functional TrkB. Brain Res 1002:120-128.

Hasegawa H, Wang F (2008) Visualizing mechanosensory endings of TrkCexpressing neurons in HS3ST-2-hPLAP mice. J Comp Neurol 511:543-556.

Hasegawa H, Abbott S, Han BX, Qi Y, Wang F (2007) Analyzing somatosensory axon projections with the sensory neuron-specific Advillin gene. J Neurosci 27:14404-14414.

Hippenmeyer S, Vrieseling E, Sigrist M, Portmann T, Laengle C, Ladle DR, Arber S (2005) A developmental switch in the response of DRG neurons to ETS transcription factor signaling. PLoS Biol 3:e159.

Hodge LK, Klassen MP, Han BX, Yiu G, Hurrell J, Howell A, Rousseau G, Lemaigre F, Tessier-Lavigne M, Wang F (2007) Retrograde BMP signaling regulates trigeminal sensory neuron identities and the formation of precise face maps. Neuron 55:572-586.

Inoue K, Ito K, Osato M, Lee B, Bae SC, Ito Y (2007) The transcription factor Runx3 represses the neurotrophin receptor TrkB during lineage commitment of dorsal root ganglion neurons. J Biol Chem 282:24175-24184.

Inoue $\mathrm{K}$, Shiga T, Ito Y (2008) Runx transcription factors in neuronal development. Neural Dev 3:20.

Kramer I, Sigrist M, de Nooij JC, Taniuchi I, Jessell TM, Arber S (2006) A role for Runx transcription factor signaling in dorsal root ganglion sensory neuron diversification. Neuron 49:379-393.

Lei L, Laub F, Lush M, Romero M, Zhou J, Luikart B, Klesse L, Ramirez F, Parada LF (2005) The zinc finger transcription factor Klf7 is required for TrkA gene expression and development of nociceptive sensory neurons. Genes Dev 19:1354-1364.

Levanon D, Brenner O, Negreanu V, Bettoun D, Woolf E, Eilam R, Lotem J, Gat
B

E18.5

PO
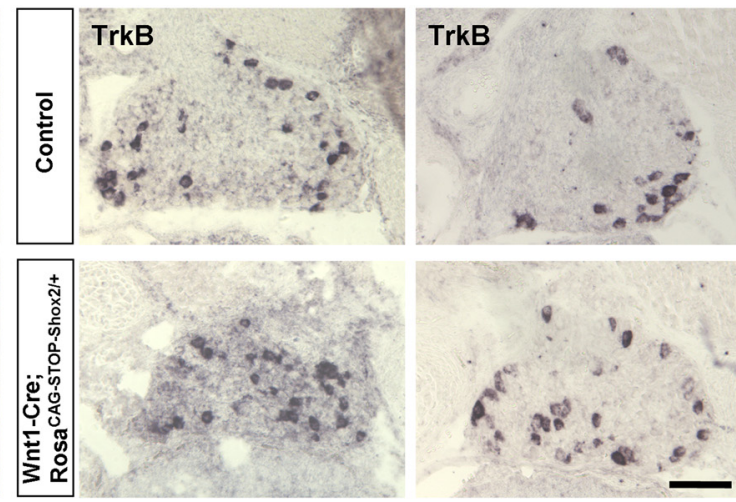

$E_{50}$
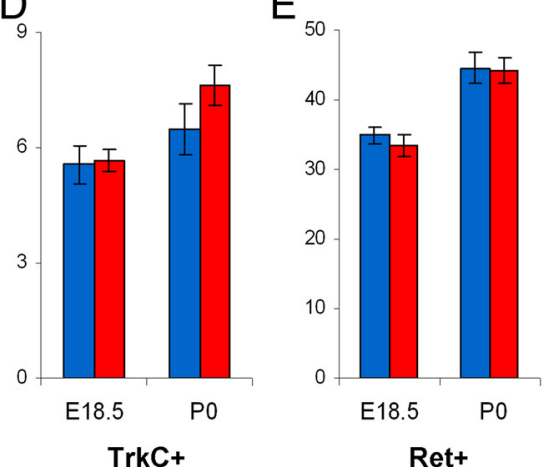

$F$

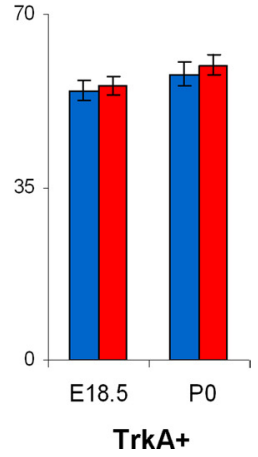

Figure 7. Overexpression of Shox2 in all sensory neurons results in a mild increase in the number of TrkB-positive cell. $\boldsymbol{A}$, tions of the numbers of TrkB- $(\boldsymbol{C})$, TrkC- $(\boldsymbol{D})$, Ret- $(\boldsymbol{E})$, and TrkA-expressing $(\boldsymbol{F})$ DRG neurons per unit area in control and Shox2 overexpression mice at E18.5 and P0. ${ }^{*} p<0.05$. Error bars represent \pm SEM. Scale bar, $100 \mu \mathrm{m}$.

U, Otto F, Speck N, Groner Y (2001) Spatial and temporal expression pattern of Runx3 (Aml2) and Runx1 (Aml1) indicates non-redundant functions during mouse embryogenesis. Mech Dev 109:413-417.

Liu Y, Yang FC, Okuda T, Dong X, Zylka MJ, Chen CL, Anderson DJ, Kuner $\mathrm{R}, \mathrm{Ma} \mathrm{Q}$ (2008) Mechanisms of compartmentalized expression of Mrg class G-protein-coupled sensory receptors. J Neurosci 28:125-132.

Luo W, Wickramasinghe SR, Savitt JM, Griffin JW, Dawson TM, Ginty DD (2007) A hierarchical NGF signaling cascade controls Ret-dependent and Ret-independent events during development of nonpeptidergic DRG neurons. Neuron 54:739-754.

Luo W, Enomoto H, Rice FL, Milbrandt J, Ginty DD (2009) Molecular identification of rapidly adapting mechanoreceptors and their developmental dependence on ret signaling. Neuron 64:841-856.

Ma Q, Fode C, Guillemot F, Anderson DJ (1999) Neurogenin1 and neurogenin2 control two distinct waves of neurogenesis in developing dorsal root ganglia. Genes Dev 13:1717-1728.

Marchini A, Rappold G, Schneider KU (2007) SHOX at a glance: from gene to protein. Arch Physiol Biochem 113:116-123.

Marmigère F, Ernfors P (2007) Specification and connectivity of neuronal subtypes in the sensory lineage. Nat Rev Neurosci 8:114-127.

Perez-Pinera $\mathrm{P}$, García-Suarez $\mathrm{O}$, Germanà $\mathrm{A}$, Díaz-Esnal B, de Carlos $\mathrm{F}$, Silos-Santiago I, del Valle ME, Cobo J, Vega JA (2008) Characterization of sensory deficits in TrkB knockout mice. Neurosci Lett 433:43-47.

Raff MC, Barres BA, Burne JF, Coles HS, Ishizaki Y, Jacobson MD (1993) Programmed cell death and the control of cell survival: lessons from the nervous system. Science 262:695-700.

Sedý J, Tseng S, Walro JM, Grim M, Kucera J (2006) ETS transcription factor ER81 is required for the Pacinian corpuscle development. Dev Dyn 235:1081-1089.

Shimizu S, Ichikawa H, Nakagawa H, Kiyomiya K, Matsuo S (2007) Effect of BDNF depletion on the formation of Ruffini endings in vibrissa follicles and the survival of their mechanoreceptive neurons in trigeminal ganglion. Brain Res 1154:95-104. 
A

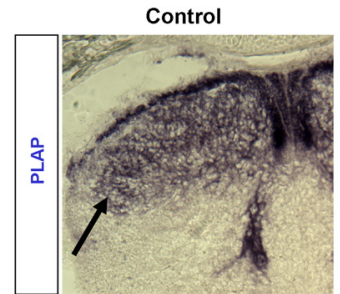

B

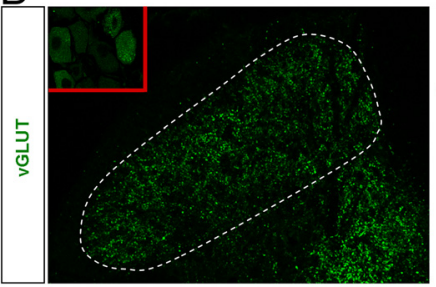

C

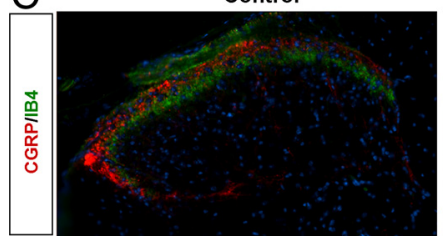

Control

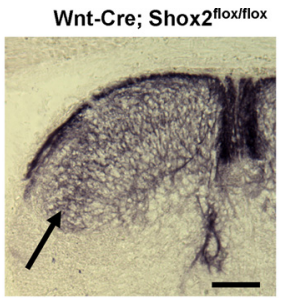

IsI-Cre; Shox2 $2^{\text {floxflox }}$

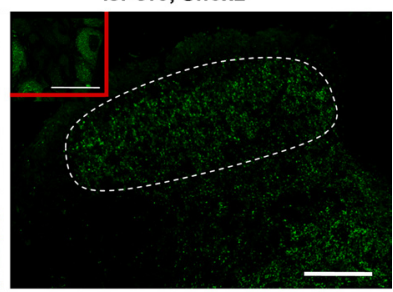

Isl-Cre; Shox $2^{\text {flox/flox }}$

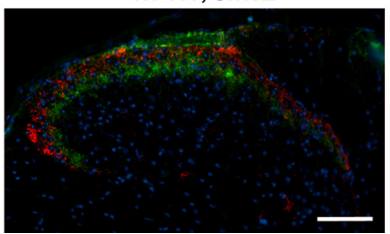

Figure 8. Reduced mechanosensory central innervation in the spinal cord in Shox2-deleted mice. $A$, Representative images of sensory afferent projections in the spinal cord from control

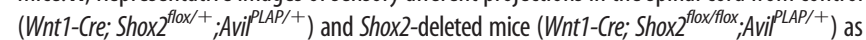
revealed by PLAP staining at PO. Arrows point to a densely stained band in layer III/IV in the control that is only moderately stained in the mutant. $\boldsymbol{B}$, Representative images of immunofluorescence staining with anti-vGluT1 in the spinal cord of control $\left(I / 1 /-\mathrm{Cre}\right.$ S Shox $\left.{ }^{f l o x /+}\right)$ and Shox2-deleted (Is/1-Cre; Shox flox/flox) mice. Inset shows the anti v-GluT1 immunofluorescence signal in the DRG of control and Shox2-deleted mice. C, Representative images of immunofluorescence staining with anti-CGRP (red) and anti-IB4 (green) in the spinal cord of control and Shoxz-deleted mice. Blue is DAPI. Scale bars: $A, C, 100 \mu \mathrm{m} ; \boldsymbol{B}, 50 \mu \mathrm{m}$.

Srinivas S, Watanabe T, Lin CS, William CM, Tanabe Y, Jessell TM, Costantini F (2001) Cre reporter strains produced by targeted insertion of EYFP and ECFP into the ROSA26 locus. BMC Dev Biol 1:4.

Sun Y, Dykes IM, Liang X, Eng SR, Evans SM, Turner EE (2008) A central

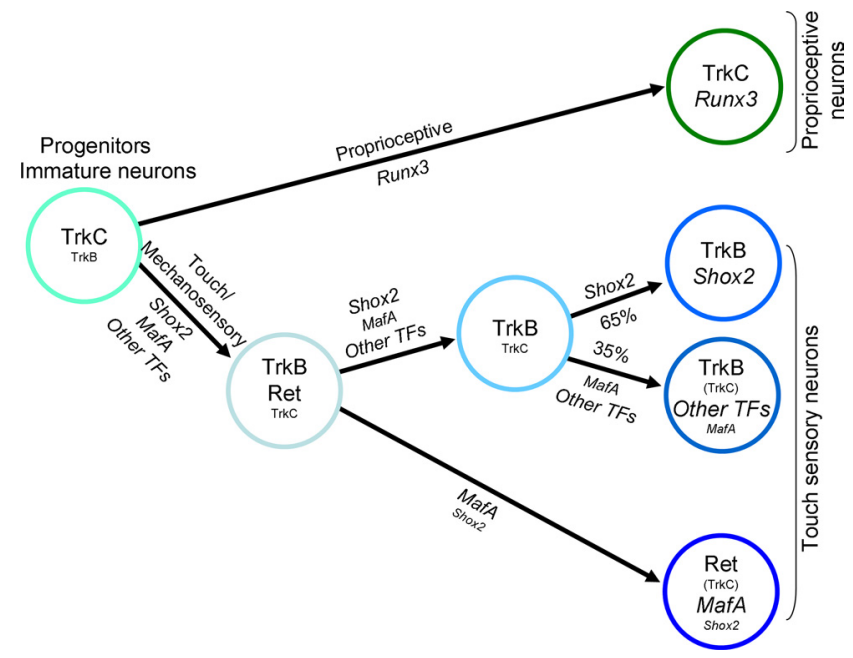

Figure 9. A model for the development and diversification of proprioceptive and touch sensory neurons. Schematic model shows the transcription factors involved in the progressive specification of TrkB/TrkC-double-positive progenitor/immature neurons into proprioceptive and different types of touch sensory neurons.

role for Islet1 in sensory neuron development linking sensory and spinal gene regulatory programs. Nat Neurosci 11:1283-1293.

Szeder V, Grim M, Halata Z, Sieber-Blum M (2003) Neural crest origin of mammalian Merkel cells. Dev Biol 253:258-263.

White FA, Keller-Peck CR, Knudson CM, Korsmeyer SJ, Snider WD (1998) Widespread elimination of naturally occurring neuronal death in Baxdeficient mice. J Neurosci 18:1428-1439.

Yang L, Cai CL, Lin L, Qyang Y, Chung C, Monteiro RM, Mummery CL, Fishman GI, Cogen A, Evans S (2006) Isl1Cre reveals a common Bmp pathway in heart and limb development. Development 133:1575-1585.

Yu L, Gu S, Alappat S, Song Y, Yan M, Zhang X, Zhang G, Jiang Y, Zhang Z, Zhang Y, Chen Y (2005) Shox2-deficient mice exhibit a rare type of incomplete clefting of the secondary palate. Development 132:4397-4406.

Zhou X, Wang L, Hasegawa H, Amin P, Han BX, Kaneko S, He Y, Wang F (2010) Deletion of PIK3C3/Vps34 in sensory neurons causes rapid neurodegeneration by disrupting the endosomal but not the autophagic pathway. Proc Natl Acad Sci U S A 107:9424-9429. 